\title{
Occurrence of non-toxic bioemulsifiers during polyhydroxyalkanoate production by Pseudomonas strains valorizing crude glycerol by-product
}

Article

Accepted Version

Creative Commons: Attribution-Noncommercial-No Derivative Works 4.0

Kourmentza, C., Araujo, D., Sevrin, C., Roma-Rodriques, C., Lia Ferreira, J., Freitas, F., Dionisio, M., Baptista, P. V., Fernandes, A. R., Grandfils, C. and Reis, M. A. M. (2019) Occurrence of non-toxic bioemulsifiers during polyhydroxyalkanoate production by Pseudomonas strains valorizing crude glycerol by-product. Bioresource Technology, 281. pp. 31-40. ISSN 0960-8524 doi:

https://doi.org/10.1016/j.biortech.2019.02.066 Available at https://centaur.reading.ac.uk/82332/

It is advisable to refer to the publisher's version if you intend to cite from the work. See Guidance on citing.

To link to this article DOI: http://dx.doi.org/10.1016/j.biortech.2019.02.066

Publisher: Elsevier

All outputs in CentAUR are protected by Intellectual Property Rights law, including copyright law. Copyright and IPR is retained by the creators or other copyright holders. Terms and conditions for use of this material are defined in 
the End User Agreement.

www.reading.ac.uk/centaur

\section{CentAUR}

Central Archive at the University of Reading

Reading's research outputs online 


\section{Accepted Manuscript}

Occurrence of non-toxic bioemulsifiers during polyhydroxyalkanoate production by Pseudomonas strains valorizing crude glycerol by-product

Constantina Kourmentza, Diana Araujo, Chantal Sevrin, Catarina RomaRodriques, Joana Lia Ferreira, Filomena Freitas, Madalena Dionisio, Pedro V. Baptista, Alexandra R. Fernandes, Christian Grandfils, Maria A.M. Reis

PII: S0960-8524(19)30266-4

DOI: https://doi.org/10.1016/j.biortech.2019.02.066

Reference: BITE 21094

To appear in: Bioresource Technology

Received Date: $\quad 19$ January 2019

Revised Date: $\quad 12$ February 2019

Accepted Date: $\quad 13$ February 2019

Please cite this article as: Kourmentza, C., Araujo, D., Sevrin, C., Roma-Rodriques, C., Lia Ferreira, J., Freitas, F., Dionisio, M., Baptista, P.V., Fernandes, A.R., Grandfils, C., Reis, M.A.M., Occurrence of non-toxic bioemulsifiers during polyhydroxyalkanoate production by Pseudomonas strains valorizing crude glycerol by-product, Bioresource Technology (2019), doi: https://doi.org/10.1016/j.biortech.2019.02.066

This is a PDF file of an unedited manuscript that has been accepted for publication. As a service to our customers we are providing this early version of the manuscript. The manuscript will undergo copyediting, typesetting, and review of the resulting proof before it is published in its final form. Please note that during the production process errors may be discovered which could affect the content, and all legal disclaimers that apply to the journal pertain. 


\section{Occurrence of non-toxic bioemulsifiers during polyhydroxyalkanoate production by}

\section{Pseudomonas strains valorizing crude glycerol by-product}

Constantina Kourmentza1, ${ }^{*}$, Diana Araujo ${ }^{2}$, Chantal Sevrin ${ }^{3}$, Catarina Roma-Rodriques ${ }^{4}$, Joana Lia Ferreira5, Filomena Freitas², Madalena Dionisio², Pedro V. Baptista4, Alexandra R. Fernandes ${ }^{4}$, Christian Grandfils ${ }^{3}$, Maria A.M. Reis ${ }^{2}$

${ }^{1}$ Food \& Bioprocessing Sciences (FaBS), Department of Food and Nutritional Sciences, School of Chemistry, Food and Pharmacy, University of Reading, RG6 6AP, Reading, UK ${ }^{2} \mathrm{UCIBIO}$, Department of Chemistry, Faculty of Science and Technology, Universidade NOVA de Lisboa, 2829-516 Caparica, Portugal

${ }^{3}$ Interfaculty Research Centre of Biomaterials (CEIB), University of Liège, B-4000 Liège, Belgium

${ }^{4}$ UCIBIO, Department of Life Sciences, Faculty of Science and Technology, Universidade NOVA de Lisboa, 2829-516 Caparica, Portugal

${ }^{5}$ LAQV-REQUIMTE, Department of Conservation and Restoration, Faculty of Science and Technology, Universidade NOVA de Lisboa, 2829-516 Caparica, Portugal

*Corresponding author: Constantina Kourmentza, Food \& Bioprocessing Sciences (FaBS), Department of Food and Nutritional Sciences, School of Chemistry, Food and Pharmacy, University of Reading, RG6 6AP, Reading, UK, ckourmentza@gmail.com;

k.kourmentza@reading.ac.uk, Tel: +44 (0) 118378 7713, Fax: +44 (0) 118378 


\section{Abstract}

While screening for polyhydroxyalkanoate (PHA) producing strains, using glycerol rich byproduct as carbon source, it was observed that extracellular polymers were also secreted into the culture broth. The scope of this study was to characterize both intracellular and extracellular polymers, produced by Pseudomonas putida NRRL B-14875 and Pseudomonas chlororaphis DSM 50083, mostly focusing on those novel extracellular polymers. It was found that they fall into the class of bioemulsifiers (BE), as they showed excellent emulsion stability against different hydrocarbons/oils at various $\mathrm{pH}$ conditions, temperature and salinity concentrations. Cytotoxicity tests revealed that BE produced by P. chlororaphis inhibited the growth of highly pigmented human melanoma cells (MNT-1) by $50 \%$ at concentrations between $150-200 \mu \mathrm{g} / \mathrm{mL}$, while no effect was observed on normal skin primary keratinocytes and melanocytes. This is the first study reporting mcl-PHA production by $P$. putida NRRL B-14785 and bioemulsifier production from both $P$. putida and $P$. chlororaphis strains.

Keywords: crude glycerol; Pseudomonas putida; Pseudomonas chlororaphis; polyhydroxyalkanoates; bioemulsifiers; cytotoxicity

\section{Introduction}

Polyhydroxyalkanoates (PHAs) are a family of polyesters that occur naturally as intracellular reserves of carbon and energy in a wide variety of prokaryotic microbial species. Their accumulation in bacterial cells is promoted when they face unfavourable growth conditions, due to the absence of nitrogen, oxygen or a nutrient essential for growth, but in the presence of excess carbon source (Kourmentza et al., 2017a). Those biopolymers have attracted interest due to their biocompatibility, biodegradability, feasibility to be produced in an eco-sustainable manner and the fact that bear similar 
physicochemical properties to petrochemical polymers such as polypropylene (PP) and lowdensity polyethylene (LDPE).

It has been reported that the total European plastics converter demand reached 49.9 million tons in 2016 with PP and LDPE representing 36.8\% of it (PlasticsEurope, 2018). PP is mainly used in food packaging, as wrapping material, hinged caps, microwave-proof containers, pipes, automotive parts, bank notes etc. while PE is used for reusable bags, trays and containers, agricultural film etc. Considering the above, gradual substitution of PP and LDPE with PHA biopolymers is expected to benefit both the environment, due to high biodegradation rates and biocompatibility, and the health of consumers since occurring degradation products are non-toxic.

In general, PHA biopolymers are categorized in two groups according to the carbon atoms present in their monomeric unit. Short-chain-length (scl-) PHA consist of 3 to 5 carbon atoms, whereas medium-chain-length (mcl-) PHA consist of longer 3-hydroxy fatty acids of 6 to 14 carbon atoms. Despite the scl-PHA wide range of applications, i.e. for the production of disposable items and food packaging materials, there is still a high demand for biomaterials with different physical and mechanical properties. mcl-PHA are elastomers and therefore suitable for high value applications, such as surgical sutures, implants, biodegradable matrices for drug delivery, etc. (Chen, 2009). mcl-PHA production is performed mainly by bacteria that belong to Pseudomonas genus since these strains possess class II PHA synthases that preferably utilize CoA thioesters of various $(R)$-3-hydroxy fatty acids comprising of 6 up to 14 carbon atoms (Rehm, 2003).

On the other hand, bioemulsifiers (BE) are classified as high molecular mass biosurfactants. They are produced extracellularly by a wide range of microorganisms and may be composed of heteropolysaccharides, lipopolysaccharides, proteins, lipoproteins, or 
complexes of those components, and are amphiphatic in nature (Kopsahelis et al., 2018;

Kourmentza et al., 2017b). They are characterized by a high number of reactive groups that have the ability to bind tightly to hydrocarbons and oil. Due to the formation of a barrier, preventing drop coalescence, they stabilize emulsions and for this reason they are often referred to as bioemuslifiers. However, those extracellular polymeric compounds are less efficient in reducing surface and interfacial tension, compared to low molecular mass biosurfactants (Uzoigwe et al., 2015).

The global emulsifiers market, including both bio-based and synthetic emulsifiers, is projected to reach 8.88 billion $\$$ by 2023 , characterized by a compound annual growth rate (CAGR) over 6\% between 2018 and 2023, mainly due to the expansion of end-use applications in the food and beverage industry, cosmetics and personal care, pharmaceuticals and industrial chemicals such as paints, coatings etc. (TechSci Research, 2018). Moreover, nowadays there is an important trend in food and healthcare industries towards the adoption of 'natural' ingredients with perceived benefits to the health of the consumers.

Simultaneous production of PHA and extracellular polymers has been reported in the past for several microorganisms. For example, the production of PHA together with alginate oligosaccharides has been reported to be feasible when Pseudomonas mendocina NK-01 was grown on glucose (Guo et al., 2011). Extracellular polysaccharides (EPS) have been produced together with poly(3-hydroxybutyrate) (PHB) by Azotobacter beijerinckii WDN-01 utilizing glucose and other sugars as sole carbon sources (Pal et al., 1999). Furthermore, in a recent study the potential of Sphingomonas sanxanigenens NX02 to simultaneously produce PHB and sphingan (Ss), an ivory-coloured extracellular polymer composed of carbohydrates, lipids and proteins, was reported for the first time (Wu et al., 2016). In 
addition, the halophilic archaeon Haloferax mediterranei is a well-known PHA producer that has the advantage of using sea water, instead of freshwater, for growth medium formulation. This strain is also known to excrete a sulphated, and thus anionic, high molecular mass EPS (Koller, 2015; Parolis et al., 1996). All the above studies highlight the potential of several microorganisms to simultaneously produce intra- and extra-cellular polymers. However, several factors may influence the carbon flux diverted to either PHA or extracellular polymers such as the composition of the cultivation media (Koller, 2015).

In this study, Pseudomonas chlororaphis DSM 50083, a well-known mcl-PHA producer (Muhr et al., 2013), as well as Pseudomonas putida NRRL B-14785, which has not been previously studied regarding PHA production, were examined on their ability to produce PHA using glycerol rich by-product (GRP) as the sole carbon source. PHAs were further characterized in terms of composition, molecular weight and thermal properties. During the fermentation, the simultaneous excretion of extracellular polymers, categorized as bioemulsifiers, was also monitored and those polymers were partially characterized regarding their composition, physicochemical properties and ability to emulsify a variety of hydrocarbons and oils under different temperatures, $\mathrm{pH}$ and $\mathrm{NaCl}$ concentrations. The cytotoxicity of these novel polymers on normal and tumour skin cells was also assessed.

\section{Materials and Methods}

\subsection{Microorganisms and media}

Pseudomonas putida NRRL B-14785 was kindly provided by the Agriculture Research Service Culture Collection (USDA). Pseudomonas chlororalphis DSM 50083 was obtained from Leibniz Institute DSMZ (German Collection of Microorganisms and Cell Cultures). Both strains were grown on a slightly modified Medium $E^{*}$ of the following composition (per 
litre): $\left(\mathrm{NH}_{4}\right)_{2} \mathrm{HPO}_{4}, 3.3 \mathrm{~g} ; \mathrm{K}_{2} \mathrm{HPO}_{4}, 5.8 \mathrm{~g} ; \mathrm{KH}_{2} \mathrm{PO}_{4}, 3.7 \mathrm{~g} ; 10 \mathrm{~mL}$ of a $100 \mathrm{mM} \mathrm{MgSO}$ solution and $1 \mathrm{~mL}$ of a micronutrient solution. The micronutrient solution had the following composition (per litre of $1 \mathrm{~N} \mathrm{HCl}$ ): $\mathrm{FeSO}_{4} \cdot 7 \mathrm{H}_{2} \mathrm{O}, 2.78 \mathrm{~g} ; \mathrm{MnCl}_{2} \cdot 4 \mathrm{H}_{2} \mathrm{O}, 1.98 \mathrm{~g} ; \mathrm{CoSO}_{4} \cdot 7 \mathrm{H}_{2} \mathrm{O}, 2.81$ g; $\mathrm{CaCl}_{2} \cdot 2 \mathrm{H}_{2} \mathrm{O}, 1.67 \mathrm{~g} ; \mathrm{CuCl}_{2} \cdot 2 \mathrm{H}_{2} \mathrm{O}, 0.17 \mathrm{~g} ; \mathrm{ZnSO}_{4} \cdot 7 \mathrm{H}_{2} \mathrm{O}, 0.29 \mathrm{~g}$. Precultures for the bioreactor experiments were prepared in shake flasks by incubating the culture in Medium $E^{*}$ supplemented with $25 \mathrm{~g} \mathrm{~L}^{-1} \mathrm{GPR}$ for $48 \mathrm{~h}$ at $30^{\circ} \mathrm{C}$ and $200 \mathrm{rpm}$. GRP containing glycerol up to $89 \%$, was supplied by Fábrica Torrejana de Biocombustíveis SA, Portugal.

\subsection{Bioreactor operation}

The experiments took place in a $10 \mathrm{~L}$ bioreactor (BioStat B-plus, Sartorius) with a working volume of $8 \mathrm{~L}$. The bacterial inoculum $(400 \mathrm{~mL})$ was inserted into the bioreactor that contained 7.6 $\mathrm{L}$ of Medium $\mathrm{E}^{*}$, modified as described above, and supplemented with $25 \mathrm{~g} \mathrm{~L}^{-1} \mathrm{GRP}$. The aeration rate ( $0.5 \mathrm{vvm}$, volume of air per volume of reactor per minute) was kept constant throughout the cultivation, while the dissolved oxygen level (DO) was controlled at $30 \%$ of air saturation by the automatic adjustment of the stirring speed (400$800 \mathrm{rpm})$. The bioreactor was operated with controlled temperature at $30.0 \pm 0.1^{\circ} \mathrm{C}$ while the $\mathrm{pH}$ was maintained at $7.0 \pm 0.1$ with the automatic addition of either base $(5 \mathrm{M} \mathrm{NaOH})$ or acid $(2 \mathrm{M} \mathrm{HCl})$. An antifoam sensor was also installed in order to suppress foam formation by the addition of Antifoam A agent (Sigma-Aldrich). GRP pulses of $15 \mathrm{~g} \mathrm{~L}^{-1}$ were supplied to the cultures during cultivation when biomass was observed to remain constant. Samples of 10$15 \mathrm{~mL}$ were collected periodically from the bioreactor for glycerol, cell dry mass (CDM), PHA and $\mathrm{BE}$ determination.

\subsection{Analytical techniques}


Culture broth samples withdrawn from the reactor, at different time points, were centrifuged at $8000 \times \mathrm{g}$, for $10 \mathrm{~min}$ in order to separate bacterial cells. Cell-free supernatant was used for the determination of glycerol and for the quantification of the BE produced. The bacterial cell pellet was used to gravimetrically estimate the CDM and PHA concentration, after being washed twice with deionized water and lyophilized. Glycerol concentration in the cell-free supernatants was determined by High-Performance Liquid Chromatography (HPLC) using an Aminex HPX-87H column (Bio-Rad Laboratories Inc.) and a Refractive Index (RI) detector as previously described (Freitas et al., 2011).

\subsection{Polyhydroxyalkanoate analysis and characterization}

\subsubsection{PHA quantification and composition}

The concentration and the PHA monomeric composition was determined by identifying its methyl-ester derivatives upon methanolysis, using a Varian CP-3800 gas chromatograph equipped with a flame ionization detector (FID) and a Carbowax capillary column $(60 \mathrm{~m} \times 0.53 \mathrm{~mm}$ I.D. $\times 1.0 \mu \mathrm{m}$ film) as previously described (Kourmentza and Kornaros, 2016). A VersaMer ${ }^{\mathrm{TM}}$ PHA copolymer, purchased from PolyFerm Canada, was used as a standard with concentrations ranging between 0.05 to $5 \mathrm{~g} \mathrm{~L}^{-1}$. The molar composition of the VersaMer ${ }^{\mathrm{TM}}$ PHA copolymer was $4 \%$ of 3-hydroxyhexanoate $(\mathrm{HHx}), 6 \%$ of 3hydroxyheptanoate ( $\mathrm{HHp}), 44 \%$ of 3-hydroxyoctanoate (HO), 27\% of 3-hydroxynonanoate (HN), 13\% of 3-hydroxydecanoate (HD) and 6\% of 3-hydroxydodecanoate (HDD).

\subsubsection{PHA extraction}

At the end of the fermentation the bacterial cells were separated from the fermentation broth by centrifugation at $8000 \times g$ for $20 \mathrm{~min}$. Cell pellets were then washed twice with deionized water and lyophilized. PHA was recovered from the biomass by Soxhlet 
extraction using chloroform ( $50 \mathrm{~mL}$ of chloroform per gram of CDM), at $80^{\circ} \mathrm{C}$ for $24 \mathrm{~h}$ as previously described. (Kourmentza et al., 2015).

\subsubsection{PHA molecular mass distribution and thermal properties}

The average molecular weight, of the PHA polymers, by weight $\left(\mathrm{M}_{\mathrm{w}}\right)$ and by number $\left(M_{n}\right)$, as well as the polydispersity index $\left(P D I=M_{w} / M_{n}\right)$ were determined by size exclusion chromatography (SEC), and Differential Scanning Calorimetry (DSC) and thermogravimetric analyses were performed as previously described (Kourmentza et al., 2018).

\subsection{Bioemulsifiers analysis and characterization}

\subsubsection{Bioemulsifiers extraction}

The cell-free supernatant obtained after centrifugation was precipitated by the addition of cold ethanol at a ratio of $1: 3 \mathrm{v} / \mathrm{v}$ (supernatant:ethanol). After mixing, the solution was kept at $4{ }^{\circ} \mathrm{C}$ overnight, in order to promote the formation of the precipitate. Precipitate was collected by filtration, re-suspended in distilled water and low molecular weight compounds that co-precipitated were removed by dialysis. Dialysis was performed using membranes with a molecular weight cut-off of 10,000 Da (SnakeSkin ${ }^{\mathrm{TM}}$, Thermo Scientific) against deionized water for 48 hours at room temperature. Dialysed supernatants were then lyophilized and stored in sealed sample tubes at room temperature until further analysis.

\subsubsection{Bioemulsifiers Fourier Transform Infrared Spectroscopy (FT-IR)}

Bioemulsifiers were analysed by infrared spectroscopy, using a Nicolet Nexus spectrophotometer coupled to a Continuum microscope and an MCT-A detector cooled by liquid nitrogen. Spectra were obtained in transmission mode from 4000 to $400 \mathrm{~cm}^{-1}$ on samples prepared in $\mathrm{KBr}$ discs, with a resolution of $8 \mathrm{~cm}^{-1}$ and 64 scans. The spectra 
obtained were analysed as acquired, as no corrections or any further manipulation was applied apart from the removal of $\mathrm{CO}_{2}$ absorption at ca. $2300-2400 \mathrm{~cm}^{-1}$ (Freitas et al., 2011).

\subsubsection{Bioemulsifiers chemical composition}

The $B E$ recovered was characterized in terms of moisture (water), inorganic, protein and lipid content as well as polysaccharide and acyl groups content and composition. Water and inorganic content were determined gravimetrically upon drying at $105^{\circ} \mathrm{C}$ for $24 \mathrm{~h}$, followed by pyrolysis at $550{ }^{\circ} \mathrm{C}$ for $48 \mathrm{~h}$, respectively (Freitas et al., 2011). Protein content was determined by the Coomassie blue method using bovine serum albumin as a standard (Bradford, 1976). Lipid content was estimated by the sulfo-phospho-vanillin method using triolein as a standard (Franzetti et al., 2012; Izard and Limberger, 2003). Total polysaccharide content was determined following the colorimetric phenol-sulfuric acid method described by Dubois et al. (DuBois et al., 1956) using glucose as a standard. In order to identify the type of fatty acids present in the bioemulsifier samples were subjected to GC-MS analysis. Lipid content was transformed to fatty acid methyl esters (FAME) following the methodology of Monteiro et al. (Monteiro et al., 2012). Mass spectra obtained were compared with mass spectral libraries and peaks were identified using retention times from a purchased FAME mixture reference standard.

For the compositional analysis of the polysaccharide part, high-performance ionexchange chromatography (HPAE) equipped with a CarboPac PA10 column and coupled with a pulsed amperometric detector (Thermo Dionex ICS-3000) was used, as previously described (Antunes et al., 2017).

Quantification of organic acyl groups was performed by HPLC using an Aminex HPX$87 \mathrm{H}$ column (Bio-Rad Laboratories Inc.) coupled to a UV/Vis detector at $210 \mathrm{~nm}$ and $30^{\circ} \mathrm{C}$. 
Succinic, acetic and pyruvic acid were used as standards at concentrations ranging between 10 to 100 ppm (Antunes et al., 2017).

\subsubsection{Bioemulsifiers molecular mass distribution and thermal properties}

Number and weight average molecular weights, as well as the polydispersity index $\left(P D I=M_{w} / M_{n}\right)$ were estimated by size exclusion chromatography (SEC) coupled with multiangle light scattering (SEC-MALS) as previously described (Antunes et al., 2017).

Thermogravimetric analysis (TGA) of the BE samples was carried out under nitrogen atmosphere with a heating rate of $20^{\circ} \mathrm{C} / \mathrm{min}$, at a temperature range from $30^{\circ} \mathrm{C}$ to $670^{\circ} \mathrm{C}$ using a Perkin Elmer TG7 system. Around $2 \mathrm{mg}$ of BE samples were placed in a platinum pan and the TGA system was calibrated in terms of weight and temperature (four standard Curie points) prior to sample analysis.

\subsubsection{Bioemulsifiers Dynamic Light Scattering (DLS)}

Dynamic Light Scattering (DLS) measurements were performed using a SZ-100 nanopartica series system (Horiba Scientific, Ltd.) with a laser of $532 \mathrm{~nm}$ and controlling temperature with a Peltier system $\left(25^{\circ} \mathrm{C}\right)$. The particle size and zeta potential were determined using an aqueous BE solution $(0.5 \% \mathrm{w} / \mathrm{v})$ filtered through a $0.22 \mu \mathrm{m}$ membrane directly into the dust-free scattering cell. Measurements were performed in triplicates at a scattering angle equal to $90^{\circ}$.

\subsubsection{Bioemulsifiers Surface tension (ST)}

The surface tension of $0.5 \% \mathrm{w} / \mathrm{v}$ aqueous BE solutions was determined by a KSV Sigma 702 tensiometer using the Du Noüy ring method (Du Noüy, 1925).

\subsubsection{Bioemulsifiers Emulsification capacity}

The ability of $\mathrm{BE}$ to form emulsions was investigated using the extracted material. Emulsification ability was first examined against kerosene using aqueous solutions of a 
range of $\mathrm{BE}$ concentrations up to $1 \% \mathrm{w} / \mathrm{v}$. The emulsification index was also tested against a variety of hydrocarbons (kerosene, benzene, cyclohexane, toluene and xylene) and oils (cedarwood, almond, soybean, olive, sunflower, vegetable and corn oil). The BEhydrocarbon systems that showed the highest emulsification activity were further evaluated at different temperatures $\left(5-70{ }^{\circ} \mathrm{C}\right), \mathrm{pH}$ and ionic strength $(0-35 \% \mathrm{NaCl} w / v)$. The ratio of $\mathrm{BE}$ to hydrophobic compound was $1: 1 \mathrm{v} / \mathrm{v}$, mixing $2 \mathrm{ml}$ of a $0.5 \% \mathrm{w} / \mathrm{v}$ aqueous BE solution and adding an equal volume of the compound tested. Mixtures were vortexed at a high speed for 2 minutes and were placed in a dark place at room temperature $\left(25.0 \pm 1.0^{\circ} \mathrm{C}\right)$ unless otherwise stated. The emulsification index was determined after 24 hours as the ratio of the height of the stable emulsion layer $\left(h_{e}\right)$ against the height of the mixture in total $\left(h_{T}\right)$ (Eq. (1)).

$$
E_{24} \%=\frac{h_{e}}{h_{T}} \times 100
$$

The emulsification capacity of aqueous solutions $(0.5 \% \mathrm{w} / \mathrm{v})$ of commercial surfactants (Triton-X, Tween-20 and Tween-80) against hydrophobic compounds, different temperatures, $\mathrm{pH}$ and $\mathrm{NaCl}$ concentrations was also evaluated for reasons of comparison.

\subsubsection{Bioemulsifier cytotoxicity analysis}

Human primary epidermal keratinocytes and melanocytes were acquired on ATCC

(Manassas, Virginia, USA) and cultured according to the producer's specifications. Human melanoma cell line MNT-1 was acquired on ThermoFisher Scientific (Waltham, Massachusetts, USA) and cultured on DMEM (Dulbecco's Modified Eagle medium, ThermoFisher Scientific) supplemented with $10 \%$ (v/v) Fetal Bovine Serum (ThermoFisher Scientific) and a mixture of $100 \mathrm{U} / \mathrm{mL}$ penicillin and $100 \mu \mathrm{g} / \mathrm{mL}$ Streptomycin (ThermoFisher 
Scientific)). Cells were maintained on T-flasks with $25 \mathrm{~cm}^{2}$ area at $37{ }^{\circ} \mathrm{C}, 5 \%(\mathrm{v} / \mathrm{v}) \mathrm{CO}_{2}$ and 99 $\%(v / v)$ relative humidity.

For the evaluation of cell viability, keratinocytes, melanocytes and melanoma (MNT1) cell cultures were plated in the appropriate medium on 96 well plates with a density of 7500 cells per well. After $24 \mathrm{~h}$ of incubation, the medium was replaced by fresh equivalent medium supplemented with increasing concentrations of the bioemulsifiers tested (concentrations ranged from 0 to $500 \mu \mathrm{g} / \mathrm{mL}$ ). After $48 \mathrm{~h}$ exposure to the polymer at $37^{\circ} \mathrm{C}, 5$ $\%(\mathrm{v} / \mathrm{v}) \mathrm{CO}_{2}$ and $99 \%(\mathrm{v} / \mathrm{v})$ relative humidity, the cell viability was accessed with the MTS assay, using the CellTiter 96 aqueous one solution cell proliferation assay (Promega, Madison, Wisconsin, USA) according to the manufacturer's instructions. This kit was composed by an inner salt of tetrazolium, MTS [3-(4,5-dimethylthiazol-2-yl)-5-(3carboxymethoxyphenyl)-2-(4-sulfophenyl)-2H-tetrazolium] and an electron coupling reagent (phenazine ethosulfate, PES). The reduction of MTS by dehydrogenase enzymes present in metabolically active cells results in the formation of formazan, a soluble compound with maximum absorbance at $490 \mathrm{~nm}\left(\mathrm{Abs}_{490}\right)$. Hence, it is considered that the amount of 490 $\mathrm{nm}$ absorbance is directly proportional to the number of living cells in culture (Fernandes et al., 2017). The percentage of cell viability was calculated by normalizing the Abs 490 of the cells treated with the polymer to the $\mathrm{Abs}_{490}$ of untreated cells.

Melanoma MNT-1 cells were seeded on a 24 -well plate at a density of 37,500 cells per well in the corresponding medium. After $24 \mathrm{~h}$, the medium was substituted by the equivalent fresh medium supplemented with 10,100 or $200 \mu \mathrm{g} / \mathrm{mL}$ polymer and incubated for another $48 \mathrm{~h}$. Afterwards, cells were detached using Tryple Express (ThermoFisher Scientific), mixed with trypan blue to a final concentration of $0.2 \%(w / v)$ (ThermoFisher Scientific) and the viable cells were counted in a hemocytometer. Trypan blue is a stain that 
only enters cells with compromised membranes, allowing the distinction between viable cells, with a translucid cytoplasm, and non-viable cells, with a blue cytoplasm (Strober, 2001). The specific growth rate of cultured cells exposed to each polymer concentration was then calculated relatively to the number of cells at $0 \mathrm{~h}$ time point.

All data were expressed as mean \pm SD from at least three independent experiments. A p-value $<0.05$, calculated using Student's t-test, was considered statistically significant.

\section{Results and discussion}

\subsection{Microbial fermentation}

As illustrated in Fig. 1, Pseudomonas putida NRRL B-14875, isolated from municipal sewage sludge in Indiana (USA), was able to produce mcl-PHAs with a polymer content in the biomass of up to $19.5 \pm 0.4 \% \mathrm{~g}$ PHAs/g CDM by the end of the experiment. According to the data obtained, PHA content in the bacterial cells reached a maximum of $22.3 \pm 0.6 \%$ g PHAs/g CDM at $68.5 \mathrm{~h}$, where PHA concentration was $1.9 \pm 0.1 \mathrm{~g} \mathrm{~L}^{-1}$. Despite the fact that glycerol was still present in the fermentation broth, PHA content started decreasing, from then on until the end of the fermentation. On the other hand, bioemulsifier production experienced a rapid increase between hours 10-21 (bioemulsifier concentration after $21 \mathrm{~h}$ of cultivation reached $\left.1.26 \pm 0.05 \mathrm{~g} \mathrm{~L}^{-1}\right)$, where also PHA started being accumulated by the biomass due to nitrogen limiting conditions. However, bioemulsifier production seems to occur mainly during the exponential growth phase, while it was shown that its concentration continued increasing with a lower rate, until the end of the experiment reaching $2.55 \pm 0.09 \mathrm{~g} \mathrm{~L}^{-1}$.

Similar results were acquired for $P$. chlororaphis DSM 50083. However, the PHA content was lower it this case, reaching a maximum of $9.0 \pm 0.1 \% \mathrm{~g} \mathrm{PHA} / \mathrm{g}$ CDM at $55 \mathrm{~h}$, 
which decreased to $5.5 \pm 0.5 \% \mathrm{~g}$ PHA/g CDM by the end of the experiment. Bioemulsifier production showed the same trend as in the case of $P$. putida, characterized by a rapid increase within the first $30 \mathrm{~h}$ of cultivation, reaching up to $1.57 \pm 0.06 \mathrm{~g} \mathrm{~L}^{-1}$. Bioemulsifier production continued until the end of the experiment where it reached $2.15 \pm 0.09 \mathrm{~g} \mathrm{~L}^{-1}$. It has been reported that $P$. chlororaphis DSM 50083 produced a high amount of ethanol soluble extracellular material during mcl-PHA production utilizing saturated biodiesel from waste animal fat (Muhr et al., 2013). It was observed that, during fed-batch cultivation, the production of this extracellular material continued during the PHA accumulation phase and increased with a higher amount of carbon source. This observation is similar to the bioemulsifier production profile that was acquired in this study. However, in the study previously reported (Muhr et al., 2013), no additional info was provided on the characterization of this extracellular material.

In general, several strains of $P$. putida have been studied regarding their ability to produce PHA when grown on glycerol by-product, as summarized in Table 1. On the other hand, PHA production by employing $P$. chlororaphis has been reported in the past using animal-derived waste (Muhr et al., 2013).

Several studies on the simultaneous production of PHA and other extracellular materials, such as sphingan (Wu et al., 2016) and other extracellular polysaccharides (Guo et al., 2011; Parolis et al., 1996) have been reported in the past. Since PHA is accumulated within the bacterial cells, separation of PHA and extracellular materials can be easily performed by conventional techniques and equipment, i.e. centrifugation, filtration etc. Such materials can be used in a wide range of high value applications and may be produced within the same bioreactor, helping to cut down on fermentation costs. The occurrence of extracellular materials during PHA production may be more frequent than expected, 
therefore there is a need to identify such polymers in order to better understand the metabolic pathways and ways to promote their individual or simultaneous production according to the product's value and application.

It should be noted here that the scope of those experiments was not to achieve optimum conditions for neither the production of PHA nor bioemulsifiers, but to identify the extracellular polymers produced and their potential uses along with the type of PHA produced.

\subsection{PHA composition and characterization}

As shown in Table 1, P. putida NRRL B-14875 produced up to $19.5 \pm 0.4 \%$ of mclPHA. The polymer consisted mainly of $64.1 \pm 1.2 \%$ of $\mathrm{HD}, 25.9 \pm 0.7 \% \mathrm{HO}$, as well as $5.6 \pm$ $0.3 \% \mathrm{HDd}$ and $4.4 \pm 0.1 \% \mathrm{HHx}$. As summarized in Table 1, the polymer produced by $P$. putida was found to have an average number molecular weight $\left(M_{n}\right)$ of $0.27 \times 10^{5} \mathrm{Da}$ and a polydispersity index of 1.53 . Glass transition temperature $\left(T_{g}\right)$ was at $-47.9^{\circ} \mathrm{C}$, melting temperature was found to be $49.5^{\circ} \mathrm{C}$ and thermal degradation was found to occur at 291.7 ${ }^{\circ} \mathrm{C}$. The polymer had a low crystallinity index of $4.9 \%$, which together with the low $T_{g}$ and high $T_{m}$, indicated the flexible/elastomeric nature of the polymer. This is the first time that PHA production by $P$. putida NRRL B-14875 has been reported.

In a similar fashion P. chlororaphis DSM 50083 produced mcl-PHA composed of 49.8 $\pm 1.0 \% \mathrm{HD}, 25.8 \pm 0.6 \% \mathrm{HDd}, 19.7 \pm 0.5 \% \mathrm{HO}$ and $4.7 \pm 0.3 \% \mathrm{HHx}$ and was amorphous, as also evidenced by the DSC analysis. $T_{g}$ was around $-46.5^{\circ} \mathrm{C}$ while a broad melting range was observed. $T_{d}$ was found at $290.3^{\circ} \mathrm{C}$.

In a previous study (Muhr et al., 2013), P. chlororaphis DSM 50083 has been reported to produce mcl-PHA from saturated biodiesel deriving from waste animal fat. The 
mcl-PHA polymer obtained consisted mainly of HO (45.69-50.64 \%) and HD (20.83-31.39 \%). Smaller portions of $\mathrm{HHx}(10.18-15.45 \%)$ and $\mathrm{HDd}(4.98-6.71 \%)$ were also present, while traces of 3-hydroxyheptanoate ( $\mathrm{HHp}, 1.12-2.99 \%)$ and 3-hydroxynonanoate (HN, 1.67 $-5.09 \%)$ were detected as well. The polymer was also characterized by a $M_{n}$ of $0.29 \times 10^{5}$ $\mathrm{Da}$, a PDI of 1.52 , a broad melting range, a $T_{g}$ of $-47.0^{\circ} \mathrm{C}$, while it was completely amorphous (Koller and Braunegg, 2015).

The physicochemical properties of the mcl-PHA produced in this study are similar to those previously reported for mcl-PHA produced by different $P$. putida (Davis et al., 2013; Fu et al., 2014; Miura et al., 2013; Poblete-Castro et al., 2014) and P. chlororaphis strains (Cerrone et al., 2015; Koller and Braunegg, 2015; Muhr et al., 2013; Walsh, 2015). $T_{m}, T_{g}$ and $T_{d}$ were within the range of temperatures reported for mcl-PHA produced by Pseudomonas strains. Low crystallinity indices are characteristic for mcl-PHA, due to their elastomeric nature and, as previously reported (Muhr et al., 2013). High thermal stability in combination with low crystallinity indices in PHA polymers are favourable characteristics i.e. for potential immune and pharmaceutical applications (Guo et al., 2011).

\subsection{Bioemulsifiers characterization and composition}

\subsubsection{Bioemulsifier FT-IR analysis}

Preliminary characterization of the bioemulsifiers via infrared spectroscopy revealed a variety of absorption bands highlighting the complexity of their structure. The presence of carbohydrate and protein moieties was indicated by the broad absorption band at 3400$3300 \mathrm{~cm}^{-1}$ due to $\mathrm{O}-\mathrm{H}$ stretching of hydroxyls for sugars and stretching of $-\mathrm{NH}_{2}$ groups for proteins. The presence of protein components is verified by the occurrence of two bands of decreasing intensity that correspond to the presence of Amide I at $1652 \mathrm{~cm}^{-1}$ and Amide II at 
$1544 \mathrm{~cm}^{-1}$, while peaks at 1456 and $1400 \mathrm{~cm}^{-1}$ can be assigned to $\mathrm{CH}_{3}$ asymmetric and $\mathrm{CH}_{3}$ symmetric bending vibration of protein respectively (Zheng et al., 2012). Bands between $1200-900 \mathrm{~cm}^{-1}$ are attributed to -C-O-C-group vibrations in the cyclic structure of carbohydrates. Absorption at $2927 \mathrm{~cm}^{-1}$ and $2962 \mathrm{~cm}^{-1}$ result from C-H asymmetric stretching vibrations of $\mathrm{CH}_{2}$ and $\mathrm{CH}_{3}$ groups respectively. $\mathrm{CH}_{2}$ symmetric stretching vibration in lipids occurs at $2855 \mathrm{~cm}^{-1}$ while an overlapped band at $1707 \mathrm{~cm}^{-1}$ indicates $C=0$ stretching of ester groups, primarily from lipids and fatty acids (Gudiña et al., 2015). The distinctive peak at $802 \mathrm{~cm}^{-1}$ is assigned to 3-6 anhydro-galactose bridge vibration, whereas the peak around $866 \mathrm{~cm}^{-1}$ reveals the presence of a-linked D-galactopyranose units. FT-IR spectra showed to have quite similar absorption bands to spectra acquired for fucose-containing EPS and the commercial polysaccharide fucogel (Freitas et al., 2011).

\subsubsection{Bioemulsifier composition}

The composition of the bioemulsifiers is shown in Table 2. It was revealed that both bioemulsifiers consist of polysaccharides, proteins and lipids. GC-MS analysis on the lipidic content of bioemulsifiers revealed the presence of tridecanoic, myristic, palmitic and stearic acids in both samples. According to the literature, the content of lipids in bacterial bioemulsifiers, occurring as a complex of carbohydrates, proteins and lipids, ranges between 2-67\% w/w (Franzetti et al., 2012; Zheng et al., 2012). Research reports on the production of bioemulsifiers by strains that belong to Pseudomonas genus are quite limited. Reddy and colleagues have reported the isolation and characterization of a bioemulsifier produced by Pseudomonas PG-1, consisting of $34 \%$ protein, $16 \%$ carbohydrate and $40 \%$ lipid, while the fatty acid profile revealed that tridecanoic acid was the major component (40.8\%), followed by palmitic acid (16.5\%), stearic acid $(6.7 \%)$ and behenic acid $(6.7 \%)$ 
(Reddy et al., 1983). Other bacterial bioemulsifiers, i.e. produced from Aeribacillus pallidus YM-1, are characterized by fatty acids such as dodecanoic, tetradecanoic, hexadecenoic and octadecanoic acid (Zheng et al., 2012). Pentadecanoic acid was also found to be a major lipidic constituent in bioemulsifiers produced by Pedobacter sp. strain MCC-Z together with small fractions of $C_{14}, C_{16}$ and $C_{18}$ fatty acids (Beltrani et al., 2015) while the lipid fraction of the bioemulsifier synthesized by Microbacterium sp. MC3B-10 consisted mainly of palmitic, stearic and oleic acid.

The composition of the polysaccharide content was also analysed and is given in Table 2. The polysaccharide part of the bioemulsifier produced by $P$. putida NRRL B-14875 (BE 14875$)$ consisted mainly of glucose $(28.9 \% \mathrm{~mol})$, galacturonic acid $(22.9 \% \mathrm{~mol})$ and rhamnose $(20.4 \% \mathrm{~mol})$. On the other hand, the bioemulsifier produced by $P$. chlororaphis DSM 50083 consisted mainly of rhamnose $(62 \% \mathrm{~mol})$ and glucose $(29 \% \mathrm{~mol})$. A recent study has reported that the structure of a lipopolysaccharide occurring from $P$. chlororaphis subsp. aureofaciens UCM B-306 consisted of rhamnose, glucose and 2-acetamido-2-deoxyglucose in a ratio of 1:0.3:0.03 and also contained derivatives of 2-amino-2-deoxygalacturonic acid (GaINA) and 2,4-diamino-2,4,6-trideoxyglucose (QuiN4N) (Zdorovenko et al., 2015). In another study, the O-specific polysaccharide of a lipopolysaccharide produced by $P$. chlororaphis subsp. aureofaciens strain M71 was a linear trisaccharide consisting of rhamnose, 2-amino-2,6-dideoxy glucose (quinovosamine) and 2-amino-2,6-dideoxygalactose (fucosamine) (Pieretti et al., 2011). GC-MS analysis also revealed the presence of 3-hydroxydecanoic, 2-hydroxydodecanoic, 3-hydroxydodecanoic, dodecannoic, tetradecanoic, hexadecenoic and octadecanoic acids.

In general, carbohydrate, lipid and protein content and composition in extracellular biopolymers do not only depend on the producing strain. It has been demonstrated that the 
presence of different hydrocarbons, used as carbon sources in the culture media ,may affect the chemical composition of the extracellular polymers produced and subsequently affect its properties (Toledo et al., 2008).

\subsubsection{Bioemulsifier molecular weight distribution}

Upon SEC-MALS analysis it was shown that the average weight molecular weight $\left(M_{w}\right)$ for the bioemulsifiers produced by $P$. putida and $P$. chlororaphis were around $6.23 \mathrm{x}$ $10^{6} \mathrm{Da}$ and $7.91 \times 10^{6}$ Da respectively. In addition, the polydispersity indices were found to be 1.17 and 1.43 for $P$. putida and $P$. chlororaphis respectively.

The molecular masses of the bioemulsifiers produced in the present study were quite high and similar to those reported for Pedobacter sp. strain MCC-Z. The specific strain was able of producing a glycolipid-protein complex with a molecular mass of approximately $7 \times 10^{6} \mathrm{Da}$ (Beltrani et al., 2015). Molecular mass was also comparable with those of extracellular polymers produced by different microorganisms. For example, microbactan, a non-toxic bioemulsifier composed of carbohydrates, proteins and lipids synthesized by Microbacterium sp. MC3B-10, has shown a high molecular weight of around $700 \mathrm{kDa}$ and a polydispersity index of 1.3.

\subsubsection{Bioemulsifier thermogravimetric analysis}

According to data obtained by the thermogravimetric analysis of the bioemulsifiers it was shown that their degradation occurred in three distinct phases. For the bioemulsifier produced by P. putida NRRL B-14875 a weight loss of $5.1 \%$ occurred initially, as the temperature rose from $35.0^{\circ} \mathrm{C}$ to $103.5^{\circ} \mathrm{C}$, due to dehydration. As the temperature continued to increase, $\mathrm{BE}$ weight remained constant until temperature reached $283.6^{\circ} \mathrm{C}$, 
where BE started to decompose, until approximately $460^{\circ} \mathrm{C}$. The total weight loss at that point reached about $46.76 \%$. Phase III occurred between $470{ }^{\circ} \mathrm{C}$ to $675^{\circ} \mathrm{C}$ where an additional $15.5 \%$ weight loss was observed until the temperature reached, that can be attributed to degradation of the remaining inorganic material. In addition, a high percentage of solid residue (around $26 \%$ ) was observed. A similar profile was obtained regarding the TGA analysis for the bioemulsifier produced by P. chlororaphis DSM 50083. Initial dehydration occurred between $35^{\circ} \mathrm{C}$ to $101.9^{\circ} \mathrm{C}$, where a weight loss of $8.0 \%$ was observed. Phase II was initiated at $279.2^{\circ} \mathrm{C}$ until $460{ }^{\circ} \mathrm{C}$ with an additional weight loss of around $46.78 \%$ while a further decrease of $19.27 \%$ took place between $470{ }^{\circ} \mathrm{C}$ and $669{ }^{\circ} \mathrm{C}$, while solid residue was around $20 \mathrm{wt} \%$. However, the thermal profiles obtained here, as well as the solid residue percentages observed, are in accordance with reports on extracellular polymers, such as bacterial (Chowdhury et al., 2011; Czemierska et al., 2016; Pooja and Chandra, 2009), cyanobacterial (Parikh and Madamwar, 2006), macro-and microalgal (Mishra et al., 2011; Pooja and Chandra, 2009)polysaccharides and plant polysaccharides (Parikh and Madamwar, 2006). For example, it has been shown by TGA analysis that the solid residue of xanthan and laminarin after $500{ }^{\circ} \mathrm{C}$ was up to $35 \%$ and 25 $\%$ respectively (Pooja and Chandra, 2009).

The high thermal stability of the polymers, together with the high percentage of solid residue, highlights their complex nature and heterogeneity. It has been observed that molecular complex configuration, in extracellular polymers, as well as the presence of cations such as $\mathrm{Na}^{+}, \mathrm{K}^{+}, \mathrm{Ca}^{2+}$, act as cross-linkers between charged sugar moieties thus resulting in slow thermal degradation after $200^{\circ} \mathrm{C}$ (Parikh and Madamwar, 2006). Previous studies have reported that the presence of uronic acids, proteins, pyruvic acid and $O$ - 
methyl, $\mathrm{O}$-acetyl and sulfate groups, that increase the complexity of those polymers, are responsible for preventing their complete degradation (Mota et al., 2013).

\subsubsection{Bioemulsifier DLS analysis}

DLS analysis of $0.5 \% \mathrm{w} / \mathrm{v}$ bioemulsifier aqueous solutions revealed that the bioemulsifiers produced by $P$. putida NRRL B14875 and P. fluorescens DSM 50083 had a quite high particle sizes, with Z-average at $3230.7 \pm 253.6 \mathrm{~nm}$ and $3651.9 \pm 62.4 \mathrm{~nm}$ respectively, while the mean peak sizes were found to be around $2558.8 \pm 283.5 \mathrm{~nm}$ and $2695.9 \pm 62.6 \mathrm{~nm}$ for $P$. putida and $P$. fluorescens respectively. Zeta potential $(\zeta)$ is an indicator of the stability of colloidal dispersions and, therefore, determines the degree of electrostatic repulsion between adjacent and similarly charged particles in a dispersion. The higher the absolute value (either positive or negative) the more stable the colloid dispersion. The bioemulsifiers produced by $P$. putida and $P$. chlororaphis showed a quite high $\zeta$ value of $-100.0 \pm 1.4 \mathrm{mV}$ and $-92.2 \pm 1.7 \mathrm{mV}$ respectively. In general, $\zeta$ values ranging from \pm 40 to \pm 60 indicate good stability whereas values of more than $\pm 61 \mathrm{mV}$ indicate excellent stability behaviour of the colloid.

\subsubsection{Bioemulsifier surface tension}

The surface tension of $0.5 \% \mathrm{w} / \mathrm{v}$ aqueous BE solutions was determined and found to be $59.6 \pm 0.8$ and $60.4 \pm 0.6 \mathrm{mN} / \mathrm{m}$ for $P$. putida and $P$. chlororaphis respectively. As mentioned before, despite the fact that bioemulsifiers have the capability to form strong and stable emulsions, their surface activity is limited, compared to low molecular weight biosurfactants (Uzoigwe et al., 2015). 


\subsubsection{Bioemulsifier emulsifying ability}

Further tests on the emulsifying abilities of those extracellular polymers were performed against a variety of hydrocarbons and oils. In Fig. 2a, emulsification index obtained after 24 hours ( $\left.\% E_{24}\right)$ against kerosene are illustrated as a function of the concentration for each bioemulsifier in aqueous solutions. For both bioemulsifiers the highest $\% E_{24}$ index against kerosene was achieved at a concentration of $0.5 \mathrm{w} / \mathrm{v}$, while the ones obtained for the bioemulsifier of $P$. chlororaphis were, in general, a bit higher compared to the ones of $P$. putida.

Furthermore, in Fig. $2 \mathrm{~b}$ it can be seen that both polymers showed a very good stability to a wide range of $\mathrm{pH}$ values between 2 to 12 . The stability of the emulsions was also evidenced over time, since the emulsification index measured after 168 hours $\left(\% E_{168}\right)$ was just a bit decreased from the one obtained after $24 \mathrm{~h}$. The long-term stability of the emulsions was assessed by keeping them in a dark place and at room temperature over a period of 50 days. Interestingly, their $\% \mathrm{E}_{168}$ was equal to $\% \mathrm{E}_{1200}$, meaning that their emulsification ability was retained for this time period (Fig. 2c).

It was also shown that, apart from kerosene, the produced bioemulsifiers were able to form emulsions with hydrocarbons such as xylene, toluene, benzene and cyclohexane, as well as oils i.e. vegetable, olive, sunflower, soybean, corn, cedarwood and almond oil. Compared to common surfactants such as Triton X-100, Tween 20 and Tween 80, the bioemulsifiers produced in this study were as effective, as shown in Fig. $2 \mathrm{~d}$.

Since bioemulsifiers were most potent against cedarwood oil, its $\% E_{24}$ was further examined at different temperatures and salinity concentrations. Both the bioemulsifiers and the reference surfactants were stable at temperatures ranging between $5-70^{\circ} \mathrm{C}$ (Fig. 2e) and salinity concentrations between $1-35 \% \mathrm{NaCl} w / v$ (Fig. 2f), with bioemulsifiers 
resulting to somewhat higher $\% \mathrm{E}_{24}$ compared to reference surfactants used. Best results were obtained in the case of the bioemulsifier produced by P. chlororaphis DSM 50083, in all cases studied.

\subsubsection{Bioemulsifier cytotoxicity}

To evaluate the cytotoxicity of the polymers normal skin-derived cell lines (human primary melanocytes and keratinocytes) and melanoma (MNT-1) cell line were subjected to crescent concentrations of the bioemulsifiers, and cell viability was accessed using the MTS assay. As illustrated in Fig. 3 the bioemulsifier produced by $P$. putida NRRL B-14875 did not affect the viability of the normal and the tumor skin-derived cell lines.

Interestingly, like $P$. putida NRRL B-14875 bioemulsifier, the bioemulsifier produced by $P$. chlororaphis DSM 50083 did not affect the viability of the normal skin-derived cell lines (keratinocytes and melanocytes). However, as shown in Fig. 4, the exposure of melanoma tumor cells (MNT-1) to more than $100 \mu \mathrm{g} / \mathrm{mL}$ of the bioemulsifier resulted in a decreased viability, reaching values lower than $50 \%$ when cells were submitted to a concentration ranging betwen $200-500 \mu \mathrm{g} / \mathrm{mL}$.

The growth rate of MNT-1 cells in the presence of P. chlororaphis DSM 50083 bioemulsifier was then examined using the Trypan Blue exclusion method (Strober, 2001). In line with the results obtained for MTS analysis, when exposed to 100 and $200 \mu \mathrm{g} / \mathrm{mL}$ of bioemulsifier, the number of MNT-1 cells reduces to half. This was reflected in a growth rate decrease from 0.41 day $^{-1}$, when cells are not exposed to the bioemulsifier, to 0.12 day $^{-1}$, when cells are exposed to $200 \mu \mathrm{g} / \mathrm{mL}$ of bioemulsifier, as shown in Fig. 5 .

The selectivity of the $P$. chlororaphis DSM 50083 bioemulsifier towards tumor cells, resulting in the decrease of viability and growth rate of melanoma cells, without affecting 
healthy human melanocytes and keratinocytes, suggests that this bioemulsifier might be suitable to use as patch for complement of melanoma treatment. However, further studies need to be conducted on this promising material to understand the mechanisms underlying the suppression of MNT-1 cells.

\section{Conclusions}

The ability of Pseudomonas strains to produce extracellular polymers along with mclPHA was showcased. The extracellular polymers were characterized as bioemulsifiers and were found to be of high molecular weight, thermally stable and were able to form strong and stable emulsions against various hydrocarbons/oils. According to cytotoxicity results, bioemulsifiers did not affect the viability of the normal skin-derived cell lines (keratinocytes and melanocytes). More interestingly, the selectivity of the bioemulsifier produced by $P$. chlororaphis DSM 50083 towards melanoma cells suggests that it might find application as patch for complement of melanoma treatment or gel-cream formulations due to its emulsification capacity.

\section{Acknowledgements}

Authors acknowledge the USDA for kindly providing the strain P. putida NRRL B-

14785, S. Rodrigues for acquiring preliminary cytotoxicity data and also thank the Unidade de Ciências Biomoleculares Aplicadas-UCIBIO, which is financed by national funds from FCT/MEC (UID/Multi/04378/2013) and co-financed by the ERDF under the PT2020 Partnership Agreement (POCI-01-0145-FEDER-007728).

\section{Funding}


This work was funded by the European Commission FP7-PEOPLE-2013-IEF-Marie

Curie Action: 'Intra-European Fellowships for Career Development' (Grant Agreement no.

625774; Acronym: SimPHAsRLs).

\section{Appendix A. Supplementary data}

E-supplementary data of this work can be found in the online version of the paper.

\section{References}

1. Antunes, S., Freitas, F., Sevrin, C., Grandfils, C., Reis, M.A.M., 2017. Production of FucoPol by Enterobacter A47 using waste tomato paste by-product as sole carbon source. Bioresour. Technol. 227, 66-73. doi:10.1016/j.biortech.2016.12.018

2. Beltrani, T., Chiavarini, S., Cicero, D.O., Grimaldi, M., Ruggeri, C., Tamburini, E., Cremisini, C., 2015. Chemical characterization and surface properties of a new bioemulsifier produced by Pedobacter sp. strain MCC-Z. Int. J. Biol. Macromol. 72, 1090-6. doi:10.1016/j.ijbiomac.2014.10.025

3. Bradford, M.M., 1976. A rapid and sensitive method for the quantitation of microgram quantities of protein utilizing the principle of protein-dye binding. Anal. Biochem. 72, 248-254. doi:https://doi.org/10.1016/0003-2697(76)90527-3

4. Cerrone, F., Davis, R., Kenny, S.T., Woods, T., O'Donovan, A., Gupta, V.K., Tuohy, M., Babu, R.P., O'Kiely, P., O'Connor, K., 2015. Use of a mannitol rich ensiled grass press juice (EGPJ) as a sole carbon source for polyhydroxyalkanoates (PHAs) production through high cell density cultivation. Bioresour. Technol. 191, 45-52. doi:10.1016/j.biortech.2015.04.128

5. Chen, G.-Q., 2009. A microbial polyhydroxyalkanoates (PHA) based bio- and materials industry. Chem. Soc. Rev. 38, 2434-2446. doi:10.1039/b812677c

6. Chowdhury, S.R., Manna, S., Saha, P., Basak, R.K., Sen, R., Roy, D., Adhikari, B., 2011. Composition analysis and material characterization of an emulsifying extracellular polysaccharide (EPS) produced by Bacillus megaterium RB-05: A hydrodynamic sediment-attached isolate of freshwater origin. J. Appl. Microbiol. 111, 1381-1393. doi:10.1111/j.1365-2672.2011.05162.x

7. Czemierska, M., Szcześ, A., Pawlik, A., Wiater, A., Jarosz-Wilkołazka, A., 2016. Production and characterisation of exopolymer from Rhodococcus opacus. Biochem. Eng. J. 112, 143-152. doi:10.1016/j.bej.2016.04.015

8. Davis, R., Kataria, R., Cerrone, F., Woods, T., Kenny, S., Donovan, A.O., Guzik, M., Shaikh, H., Duane, G., Kumar, V., Tuohy, M.G., Babu, R., Casey, E., Connor, K.E.O., 2013. Conversion of grass biomass into fermentable sugars and its utilization for medium chain length polyhydroxyalkanoate ( $\mathrm{mcl}-\mathrm{PHA}$ ) production by Pseudomonas strains. Bioresour. Technol. 150, 202-209. doi:10.1016/j.biortech.2013.10.001

9. Du Noüy, P.L., 1925. An interfacial tensiometer for universal use. J. Gen. Physiol. 
625-632.

10. DuBois, M., Gilles, K. a., Hamilton, J.K., Rebers, P. a., Smith, F., 1956. Colorimetric method for determination of sugars and related substances. Anal. Chem. 28, 350356. doi:10.1021/ac60111a017

11. Fernandes, A.R., Jesus, J., Martins, P., Figueiredo, S., Rosa, D., Martins, L.M.R.D.R.S. Luísa, M., Carvalheiro, M.C., Costa, P.M., Baptista, P. V, 2017. Multifunctional goldnanoparticles: A nanovectorization tool for the targeted delivery of novel chemotherapeutic agents. J. Control. Release 245, 52-61. doi:10.1016/j.jconrel.2016.11.021

12. Franzetti, A., Gandolfi, I., Raimondi, C., Bestetti, G., Banat, I.M., Smyth, T.J., Papacchini, M., Cavallo, M., Fracchia, L., 2012. Environmental fate, toxicity, characteristics and potential applications of novel bioemulsifiers produced by Variovorax paradoxus 7bCT5. Bioresour. Technol. 108, 245-51. doi:10.1016/j.biortech.2012.01.005

13. Freitas, F., Alves, V.D., Torres, C.A.V., Cruz, M., Sousa, I., Melo, M.J., Ramos, A.M., Reis, M.A.M., 2011. Fucose-containing exopolysaccharide produced by the newly isolated Enterobacter strain A47 DSM 23139. Carbohydr. Polym. 83, 159-165. doi:10.1016/j.carbpol.2010.07.034

14. Fu, J., Sharma, U., Sparling, R., Cicek, N., Levin, D.B., 2014. Evaluation of mediumchain-length polyhydroxyalkanoate production by Pseudomonas putida LS46 using biodiesel 468, 461-468.

15. Gudiña, E.J., Pereira, J.F.B., Costa, R., Evtuguin, D. V, Coutinho, J.A.P., Teixeira, J.A., Rodrigues, L.R., 2015. Novel bioemulsifier produced by a Paenibacillus strain isolated from crude oil. Microb. Cell Fact. 14, 14. doi:10.1186/s12934-015-0197-5

16. Guo, W., Song, C., Kong, M., Geng, W., Wang, Y., Wang, S., 2011. Simultaneous production and characterization of medium-chain-length polyhydroxyalkanoates and alginate oligosaccharides by Pseudomonas mendocina NK-01. Appl. Microbiol. Biotechnol. 92, 791-801. doi:10.1007/s00253-011-3333-0

17. Izard, J., Limberger, R.J., 2003. Rapid screening method for quantitation of bacterial cell lipids from whole cells. J. Microbiol. Methods 55, 411-418. doi:10.1016/S01677012(03)00193-3

18. Koller, M., 2015. Study on the Production and Re-use of Poly(3-hydroxybutyrate-co3- hydroxyvalerate) and Extracellular Polysaccharide by the Archaeon Haloferax mediterranei Strain DSM 1411. Chem. Biochem. Eng. Q. 29, 87-98. doi:10.15255/CABEQ.2014.2058

19. Koller, M., Braunegg, G., 2015. Biomediated production of structurally diverse poly(hydroxyalkanoates) from surplus streams of the animal processing industry. Polimery/Polymers 60, 298-308. doi:10.14314/polimery.2015.298

20. Kopsahelis, A., Kourmentza, C., Zafiri, C., Kornaros, M., 2018. Gate-to-gate life cycle assessment (LCA) of biosurfactants and bioplasticizers production via biotechnological exploitation of fats and waste oils. J. Chem. Technol. Biotechnol. doi:10.1002/jctb.5633

21. Kourmentza, C., Costa, J., Azevedo, Z., Servin, C., Grandfils, C., De Freitas, V., Reis, M.A.M., 2018. Burkholderia thailandensis as a microbial cell factory for the bioconversion of used cooking oil to polyhydroxyalkanoates and rhamnolipids. Bioresour. Technol. 247, 829-837. doi:10.1016/j.biortech.2017.09.138

22. Kourmentza, C., Freitas, F., Alves, V., Reis, M.A.M., 2017a. Microbial Conversion of 
Waste and Surplus Materials into High- Value Added Products: The Case of Biosurfactants, in: Kalia, V.C., Kumar, P. (Eds.), Microbial Appications Vol.1 Bioremediation and Bioenergy. Springer International Publishing, pp. 29-78. doi:10.1007/978-3-319-52666-9_2

23. Kourmentza, C., Plácido, J., Venetsaneas, N., Burniol-Figols, A., Varrone, C., Gavala, H.N., Reis, M.A.M., 2017b. Recent Advances and Challenges towards Sustainable Polyhydroxyalkanoate (PHA) Production. Bioengineering 4, 55. doi:10.3390/bioengineering4020055

24. Kourmentza, C., Kornaros, M., 2016. Biotransformation of volatile fatty acids to polyhydroxyalkanoates by employing mixed microbial consortia: The effect of $\mathrm{pH}$ and carbon source. Bioresour. Technol. doi:10.1016/j.biortech.2016.10.014

25. Kourmentza, C., Ntaikou, I., Lyberatos, G., Kornaros, M., 2015. Polyhydroxyalkanoates from Pseudomonas sp. using synthetic and olive mill wastewater under limiting conditions. Int. J. Biol. Macromol. 74, 202-10. doi:10.1016/j.ijbiomac.2014.12.032

26. Mishra, A., Kavita, K., Jha, B., 2011. Characterization of extracellular polymeric substances produced by micro-algae Dunaliella salina. Carbohydr. Polym. 83, 852857. doi:10.1016/j.carbpol.2010.08.067

27. Miura, T., Ishii, D., Nakaoki, T., 2013. Production of Poly ( 3-hydroxyalkanoate ) s by Pseudomonas putida Cultivated in a Glycerol / Nonanoic Acid-Containing Medium. J Polym Env. 21, 760-765. doi:10.1007/s10924-013-0588-9

28. Monteiro, A.D.S., Domingues, V.S., Souza, M.V.D., Lula, I., Gonçalves, D.B., Siqueira, E.P. De, Lúcia, V., 2012. Bioconversion of biodiesel refinery waste in the bioemulsifier by Trichosporon mycotoxinivorans CLA2. Biotechnol. Biofuels 5, 1. doi:10.1186/1754-6834-5-29

29. Mota, R., Guimarães, R., Büttel, Z., Rossi, F., Colica, G., Silva, C.J., Santos, C., Gales, L., Zille, A., Philippis, R. De, Pereira, S.B., Tamagnini, P., 2013. Production and characterization of extracellular carbohydrate polymer from. Carbohydr. Polym. 92, 1408-1415. doi:10.1016/j.carbpol.2012.10.070

30. Muhr, A., Rechberger, E.M., Salerno, A., Reiterer, A., Malli, K., Strohmeier, K., Schober, S., Mittelbach, M., Koller, M., 2013. Novel Description of mcl-PHA Biosynthesis by Pseudomonas chlororaphis from Animal-Derived Waste. J. Biotechnol. 165, 45-51. doi:10.1016/j.jbiotec.2013.02.003

31. Pal, S., Manna, A., Paul, A.K., 1999. Production of poly (b-hydroxybutyric acid) and exopolysaccharide by Azotobacter beijerinckii WDN-01. World J. Microbiol. Biotechnol. 15, 11-16. doi:10.1023/A:1008825009825

32. Parikh, A., Madamwar, D., 2006. Partial characterization of extracellular polysaccharides from cyanobacteria $97,1822-1827$. doi:10.1016/j.biortech.2005.09.008

33. Parolis, H., Parolis, L.A., Boan, I.F., Rodriguez-Valera, F., Widmalm, G., Manca, M.C., Jansson, P.E., Sutherland, I.W., 1996. The structure of the exopolysaccharide produced by the halophilic Archaeon Haloferax mediterranei strain R4 (ATCC 33500). Carbohydr. Res. 295, 147-156.

34. Pieretti, G., Puopolo, G., Carillo, S., Zoina, A., Lanzetta, R., Parrilli, M., Evidente, A., Corsaro, M.M., 2011. Structural characterization of the O-chain polysaccharide from an environmentally beneficial bacterium Pseudomonas chlororaphis subsp. aureofaciens strain M71. Carbohydr. Res. 346, 2705-2709. 
doi:10.1016/j.carres.2011.09.027

35. PlasticsEurope, 2018. Plastics - the Facts 2017 [WWW Document]. URL https://www.plasticseurope.org/application/files/5715/1717/4180/Plastics_the_fact s_2017_FINAL_for_website_one_page.pdf

36. Poblete-Castro, I., Binger, D., Oehlert, R., Rohde, M., 2014. Comparison of mclpoly(3-hydroxyalkanoates) synthesis by different pseudomonas putida strains from crude glycerol: Citrate accumulates at high titer under PHA-producing conditions. BMC Biotechnol. 14, 1-11. doi:10.1186/s12896-014-0110-z

37. Pooja, K.P., Chandra, T.S., 2009. Production and partial characterization of a novel capsular polysaccharide KP-EPS produced by Paenibacillus pabuli strain ATSKP 835841. doi:10.1007/s11274-009-9954-0

38. Reddy, P.G., Singh, H.D., Pathak, M.G., Bhagat, S.D., Baruah, J.N., 1983. Isolation and Functional Characterization of Hydrocarbon Emulsifying and Solubilizing Factors Produced by a Pseudomonas Species XXV, 387-401.

39. Rehm, B.H.A., 2003. Polyester synthases: natural catalysts for plastics. Biochem. J. 376, 15-33. doi:10.1042/bj20031254

40. Strober, W., 2001. Trypan Blue Exclusion Test of Cell Viability. Curr. Protoc. Immunol. 21, A.3B.1-A.3B.2. doi:10.1002/0471142735.ima03bs21

41. TechSci Research, 2018. Global Emulsifiers Market, By Source (Bio-Based Emulsifiers and Synthetic Emulsifiers), By Application (Food Emulsifiers, Cosmetics \& Personal Care, Oilfield Chemical, Pharmaceutical, and Agrochemical), By Company and By Geography, Forecast \& Opportunitie.

42. Toledo, F.L., Gonzalez-Lopez, J., Calvo, C., 2008. Production of bioemulsifier by Bacillus subtilis, Alcaligenes faecalis and Enterobacter species in liquid culture. Bioresour. Technol. 99, 8470-5. doi:10.1016/j.biortech.2007.08.055

43. Uzoigwe, C., Burgess, J.G., Ennis, C.J., Rahman, P.K.S.M., 2015. Bioemulsifiers are not biosurfactants and require different screening approaches. Front. Microbiol. 6, 1-6. doi:10.3389/fmicb.2015.00245

44. Walsh, M., 2015. Plant Oils and Products of Their Hydrolysis as Substrates for Polyhydroxyalkanoate Synthesis. Chem. Biochem. Eng. Q. 29, 123-133. doi:10.15255/CABEQ.2014.2252

45. Wu, M., Li, G., Huang, H., Chen, S., Luo, Y., Zhang, W., Li, K., Zhou, J., Ma, T., 2016. The simultaneous production of sphingan $\mathrm{Ss}$ and poly(R-3-hydroxybutyrate) in Sphingomonas sanxanigenens NX02. Int. J. Biol. Macromol. 82, 361-368. doi:10.1016/j.ijbiomac.2015.09.071

46. Zdorovenko, E.L., Varbanets, L.D., Shashkov, A.S., Kiprianova, E.A., Knirel, Y.A., 2015. Structure of the O-polysaccharide of the lipopolysaccharide of Pseudomonas chlororaphis subsp. aureofaciens UCM B-306. Carbohydr. Res. 410, 47-50. doi:10.1016/j.carres.2015.03.019

47. Zheng, C., Li, Z., Su, J., Zhang, R., Liu, C., Zhao, M., 2012. Characterization and emulsifying property of a novel bioemulsifier by Aeribacillus pallidus YM-1. J. Appl. Microbiol. 113, 44-51. doi:10.1111/j.1365-2672.2012.05313.x 
Table 1: Monomeric composition and physicochemical properties of of mcl-PHA produced by P. putida NRRL B-14875 and P. chlororaphis DSM 50083.

\begin{tabular}{lcc}
\hline \hline Parameter & P. putida NRRL B-14875 & P. chlororaphis DSM 50083 \\
\hline \hline PHA content wt.\% & $19.5 \pm 0.4$ & $5.5 \pm 0.5$ \\
\hline PHA composition (\% mol) & & \\
HHx & $4.4 \pm 0.1$ & $4.7 \pm 0.3$ \\
HO & $25.9 \pm 0.7$ & $19.7 \pm 0.5$ \\
$\mathrm{HD}$ & $64.1 \pm 1.2$ & $49.8 \pm 1.0$ \\
$\mathrm{HDd}$ & $5.6 \pm 0.3$ & $25.8 \pm 0.6$ \\
\hline $\mathrm{M}_{\mathrm{w}}\left(\times 10^{5} \mathrm{Da}\right)$ & 0.29 & 0.27 \\
\hline $\mathrm{M}_{\mathrm{n}}\left(\times 10^{5} \mathrm{Da}\right)$ & 0.19 & 0.17 \\
\hline $\mathrm{PDI}$ & 1.52 & 1.53 \\
\hline$T_{g}\left({ }^{\circ} \mathrm{C}\right)$ & -47.9 & -46.5 \\
\hline$T_{m}\left({ }^{\circ} \mathrm{C}\right)$ & 49.5 & broad melting range \\
\hline$T_{d}\left({ }^{\circ} \mathrm{C}\right)$ & 291.7 & 290.3 \\
\hline$X_{c}(\%)$ & 4.9 & - \\
\hline \hline
\end{tabular}


Table 2: Composition of the bioemulsifiers produced by $P$. putida NRRL B-14875 and P. chlororaphis DSM 50083 utilizing GRP as the sole carbon source.

\begin{tabular}{|c|c|c|c|c|c|c|}
\hline & Moisture & Inorganics & Proteins & Lipids & Acyl groups & Carbohydrates \\
\hline Bioemulsifier & \multicolumn{6}{|c|}{$\% w / w$} \\
\hline \multicolumn{7}{|l|}{ NRRL B-14875 } \\
\hline \multirow[t]{7}{*}{ (BE-14875) } & & & & Presence of: & $\%$ molar composition & $\%$ molar composition \\
\hline & & & & Tridecanoic acid & Acetyl: $55.8 \pm 8.1$ & Fucose: $15.7 \pm 0.1$ \\
\hline & & & & Tetradecanoic acid & Pyruvyl: $44.2 \pm 4.4$ & Rhamnose: $20.4 \pm 0.4$ \\
\hline & & & & Hexadecanoic acid & & Glucosamine: $9.0 \pm 1.9$ \\
\hline & & & & Octadecanoic acid & & Glucose: $28.9 \pm 0.2$ \\
\hline & & & & & & Galacturonic acid: $22.9 \pm 1.5$ \\
\hline & & & & & & Glucuronic acid: $3.1 \pm 0.2$ \\
\hline P. chlororaphis & $8.3 \pm 0.2$ & $20.0 \pm 0.2$ & $25.7 \pm 0.5$ & $23.2 \pm 0.8$ & $1.34 \pm 0.03$ & $13.5 \pm 0.3$ \\
\hline \multicolumn{7}{|l|}{ DSM 50083} \\
\hline \multirow[t]{6}{*}{ (BE-50083) } & & & & Presence of: & $\%$ molar composition & $\%$ molar composition \\
\hline & & & & Tridecanoic acid & Acetyl: $57.2 \pm 1.9$ & Rhamnose: $62.0 \pm 0.5$ \\
\hline & & & & Tetradecanoic acid & Pyruvyl: $42.8 \pm 0.6$ & Glucosamine: $2.3 \pm 0.0$ \\
\hline & & & & anoic acid & & Glucose: $29.0 \pm 0.1$ \\
\hline & & & & Octadecanoic acid & & Mannose: $4.6 \pm 0.4$ \\
\hline & & & & & & Galacturonic acid: $2.1 \pm 0.1$ \\
\hline
\end{tabular}



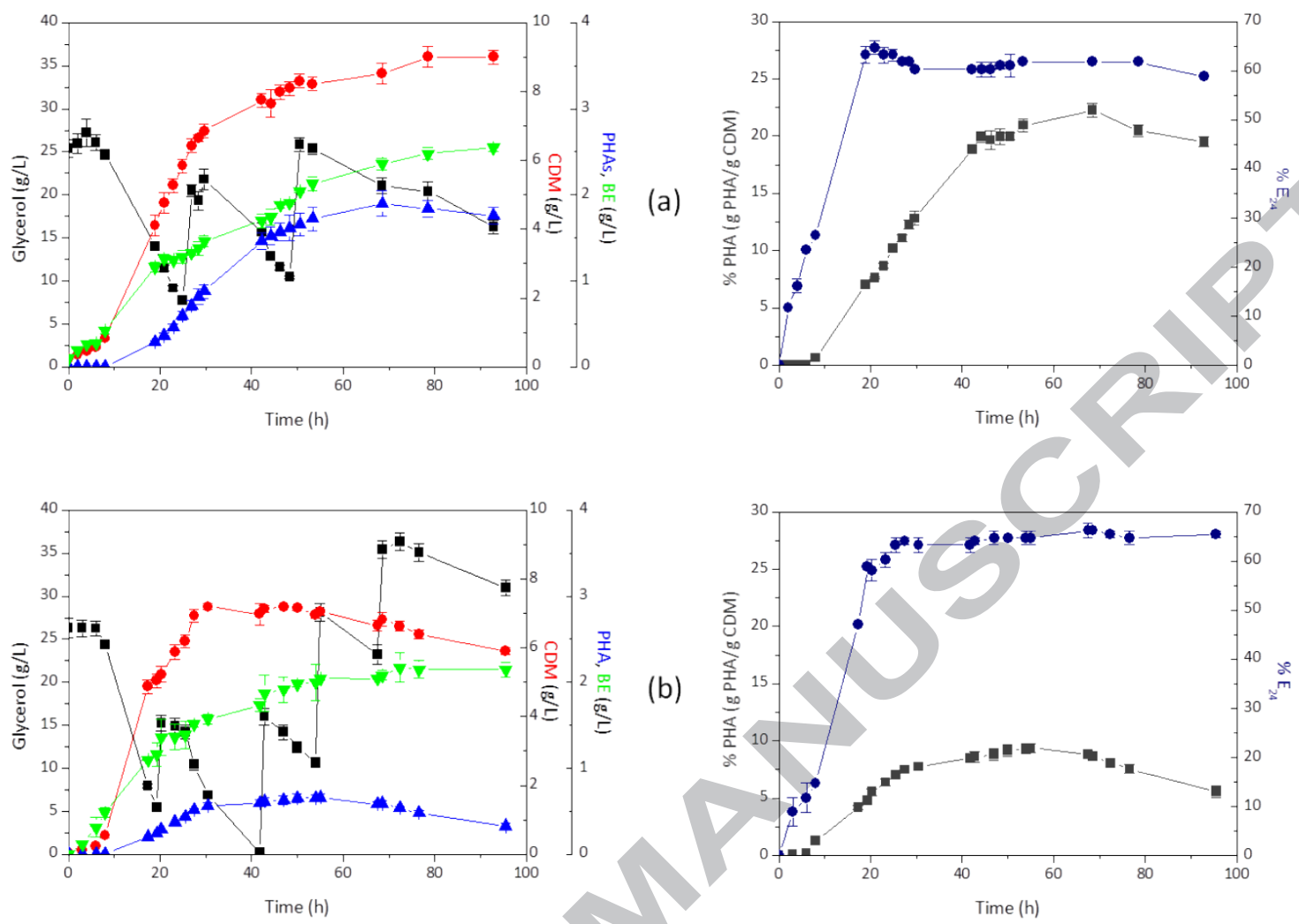

Fig. 1. Fed-batch production of mcl-PHA and bioemulsifier by (a) Pseudomonas putida NRRL B-14875 and (b) Pseudomonas chlororaphis DSM 50083 using GRP as the sole carbon source

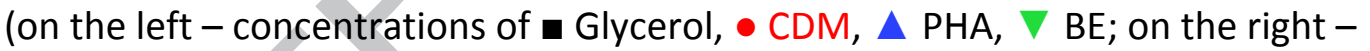
percentages of intracellular PHA content, • emulsification index \% $\left.\mathrm{E}_{24}\right)$. 

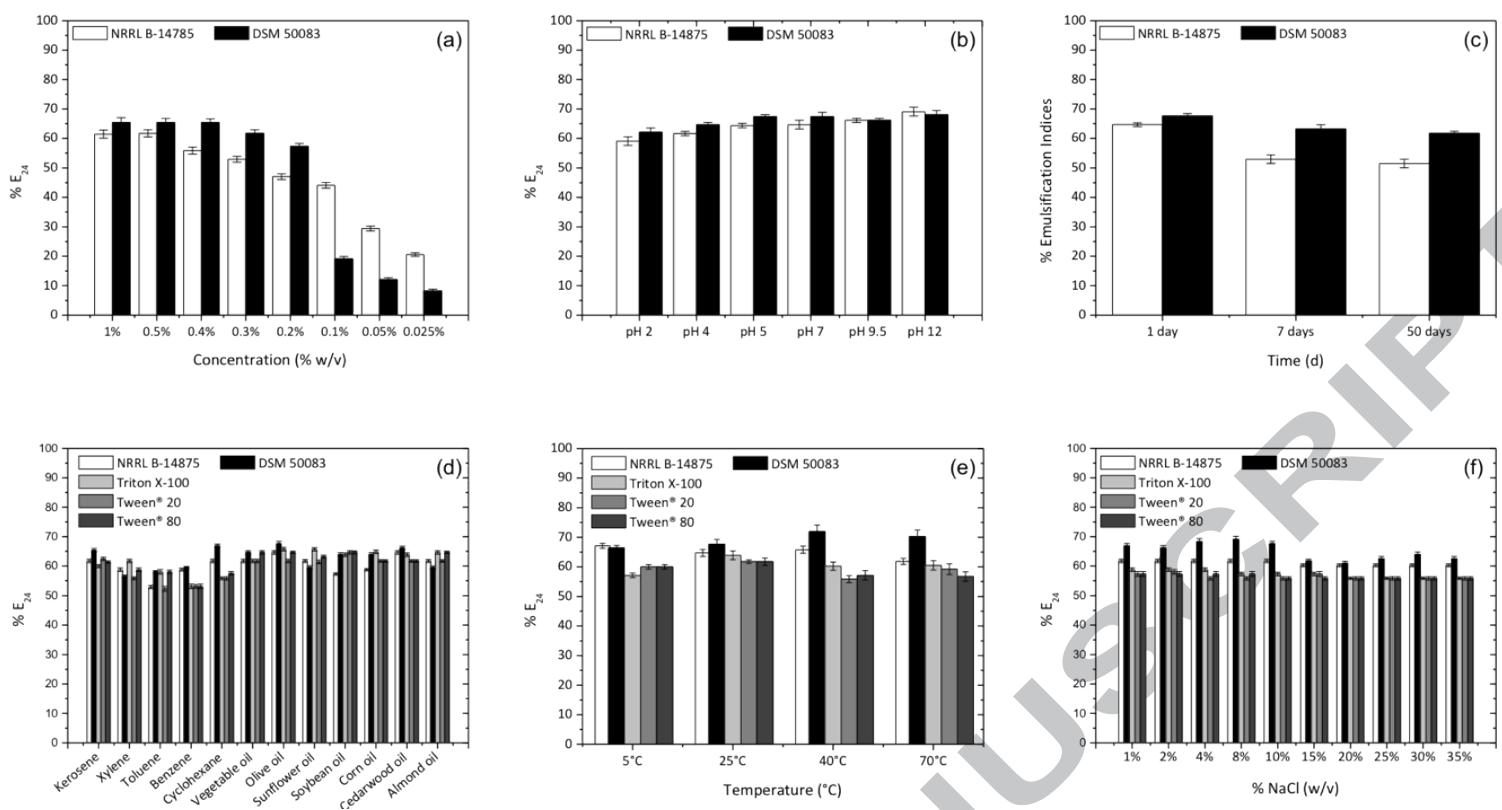

Fig. 2. Emulsification indices, $\% E_{24}$, of bioemulsifiers produced by strains $P$. putida NRRL B14785 and $P$. chlororaphis DSM 50083: (a) \% $\mathrm{E}_{24}$ against kerosene at different bioemulsifier concentrations, (b) \% $\mathrm{E}_{24}$ against kerosene at different $\mathrm{pH}$, (c) \% emulsification indices after 1, 7 and 50 days, (d) \% $E_{24}$ against various hydrocarbons and oils, (e) \% $E_{24}$ against cedarwood oil at different temperatures and (f) $\% \mathrm{E}_{24}$ against cedarwood oil at various salinity concentrations. 

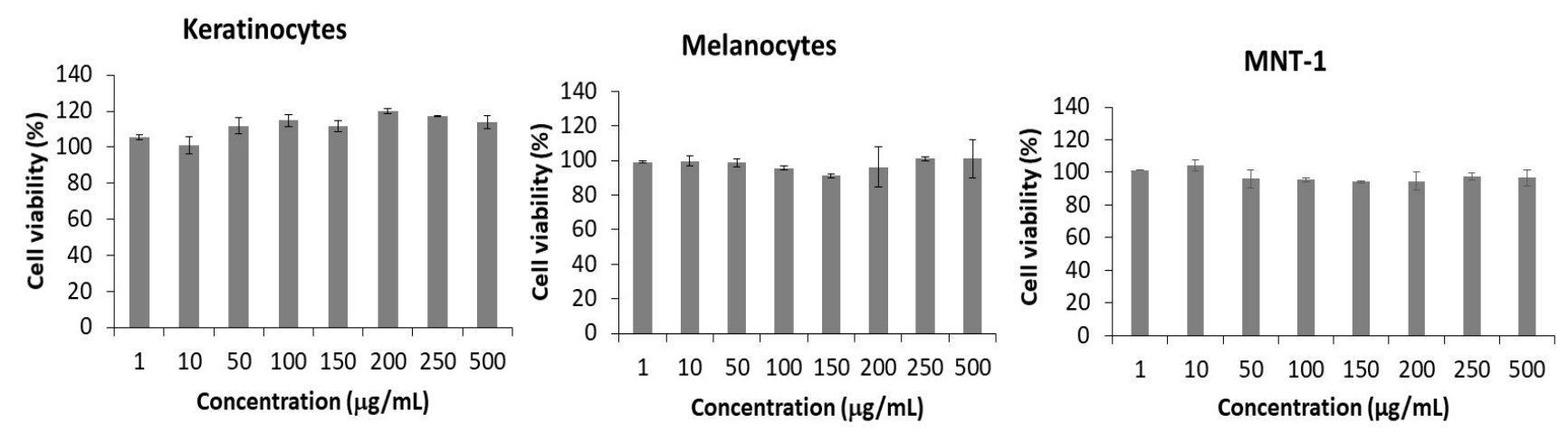

Fig. 3. Cytotoxicity P. putida NRRL B-14875 bioemulsifier in human primary keratinocytes, melanocytes, and in human melanoma cell line, MNT-1. The cell viability was assessed using the MTS assay after $48 \mathrm{~h}$ exposure of cells to crescent concentrations of the bioemulsifier. Presented data are expressed as the mean \pm SD of three independent experiments after normalization against untreated cells. 

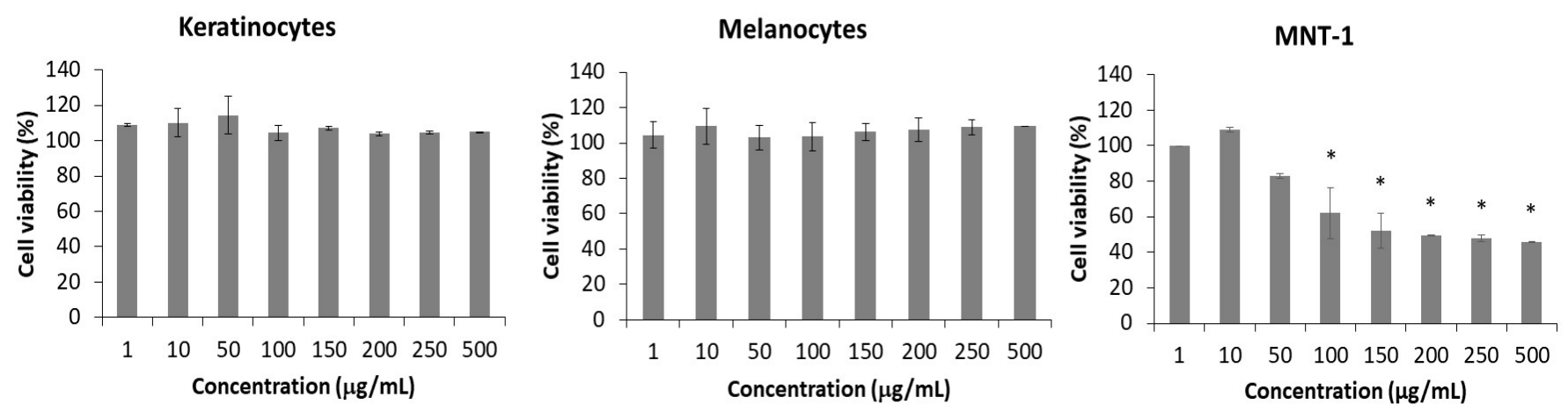

Fig. 4. Cytotoxicity of $P$. chlororaphis DSM 50083 bioemulsifier in human primary

keratinocytes, melanocytes, and in human melanoma cell line, MNT-1. The cell viability was assessed using the MTS assay after $48 \mathrm{~h}$ exposure of cells to crescent concentrations of the bioemulsifier. Presented data are expressed as the mean \pm SD of three independent experiments after normalization against untreated cells. ${ }^{*} p<0.05$ relative to control of each cell line. 


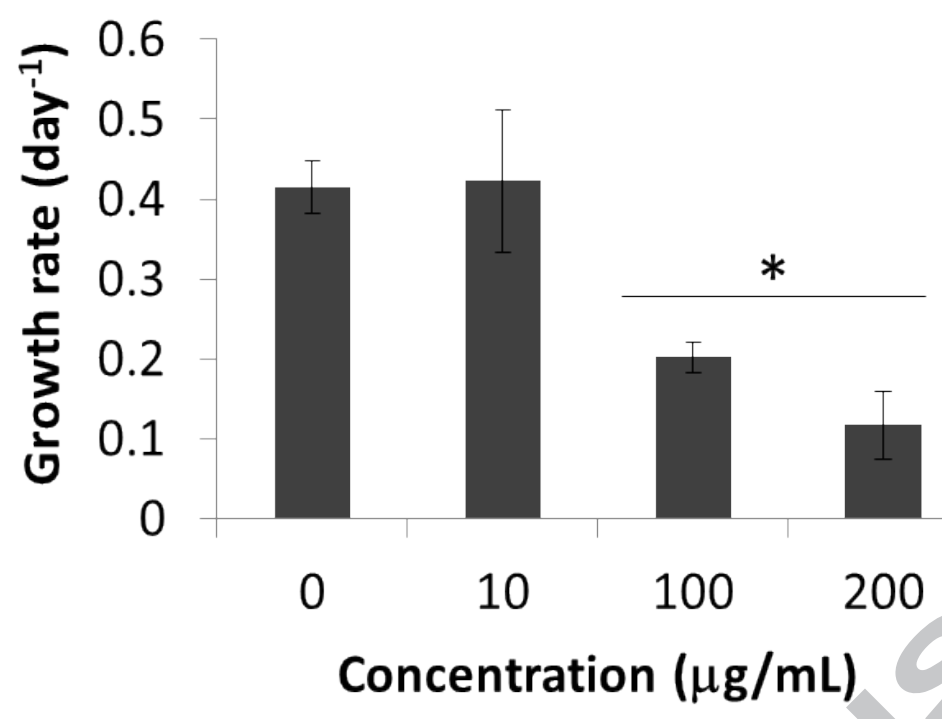

Fig. 5. Growth rate of human melanoma cell line MNT-1 after $48 \mathrm{~h}$ exposure to increasing concentrations of $P$. chlororaphis DSM 50083 bioemulsifier $(0-200 \mu \mathrm{g} / \mathrm{mL}$ ). The number of cells were acquired using the Trypan Blue exclusion method and growth rate was calculated related to the initial number of cells at time point 0 . Bars represent the average \pm SD of three independent experiments. * $\mathrm{p}$-value $<0.05$ relative to untreated cells.

\section{Highlights}

- mcl-PHA production by P. putida NRRL B-14785 is described for the first time

- P. putida and P. chlororaphis produced extracellular polymers together with mclPHA

- Extracellular polymers were found to be efficient bioemulsifiers

- Bioemulsifiers showed no cytotoxicity on normal skin primary cell lines

- Bioemulsifier by P. chororaphis halved the growth rate of MNT-1 melanoma cells

Graphical Abstract 


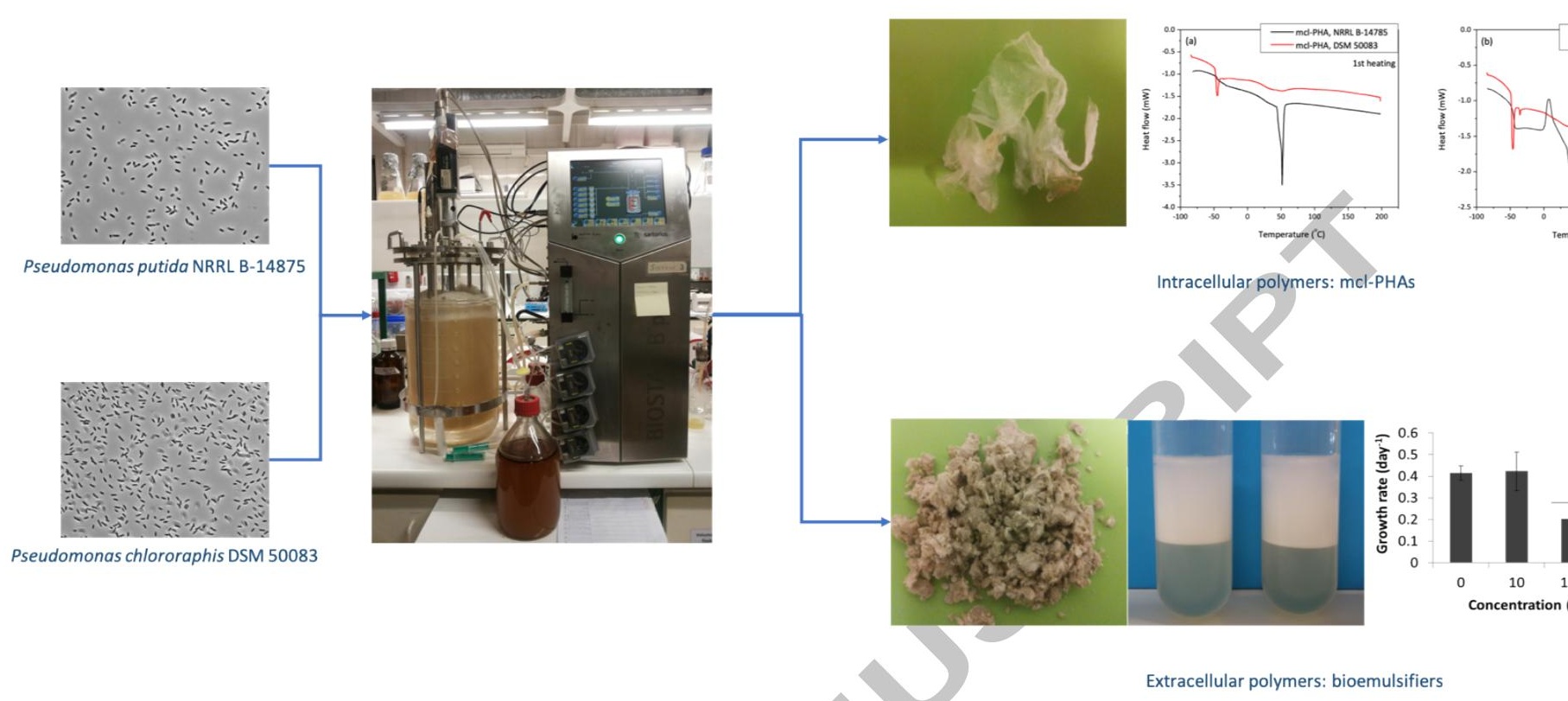

